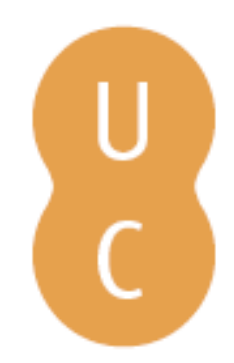

\title{
pompalina
}

\section{Quando as fontes nos falam sobre os documentos: dois estudos de caso} relacionados à ciência coimbrã

\author{
Autor(es): $\quad$ Alfonso-Goldfarb, Ana Maria; Ferraz, Marcia H. M.; Goldfarb, José L. \\ Publicado por: Imprensa da Universidade de Coimbra \\ URL \\ persistente: URI:http://hdl.handle.net/10316.2/38445 \\ DOI: $\quad$ DOI:http://dx.doi.org/10.14195/978-989-26-0764-1_9 \\ Accessed : $\quad$ 26-Apr-2023 10:25:01
}

A navegação consulta e descarregamento dos títulos inseridos nas Bibliotecas Digitais UC Digitalis, UC Pombalina e UC Impactum, pressupõem a aceitação plena e sem reservas dos Termos e Condições de Uso destas Bibliotecas Digitais, disponíveis em https://digitalis.uc.pt/pt-pt/termos.

Conforme exposto nos referidos Termos e Condições de Uso, o descarregamento de títulos de acesso restrito requer uma licença válida de autorização devendo o utilizador aceder ao(s) documento(s) a partir de um endereço de IP da instituição detentora da supramencionada licença.

Ao utilizador é apenas permitido o descarregamento para uso pessoal, pelo que o emprego do(s) título(s) descarregado(s) para outro fim, designadamente comercial, carece de autorização do respetivo autor ou editor da obra.

Na medida em que todas as obras da UC Digitalis se encontram protegidas pelo Código do Direito de Autor e Direitos Conexos e demais legislação aplicável, toda a cópia, parcial ou total, deste documento, nos casos em que é legalmente admitida, deverá conter ou fazer-se acompanhar por este aviso.

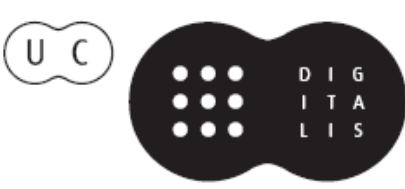


Pontifícia Universidade Católica de São Paulo

aagold@dialdata.com.br; mhferraz@pucsp.br; jlgoldfarb@dialdata.com.br

\section{Quando as Fontes nos Falam Sobre os Documentos: Dois Estudos de Caso Relacionados à CiênCia Coimbrā}

\section{Ana Maria Alfonso-Goldfarb, Marcia H.M. Ferraz e José L. Goldfarb}

Com frequência considerado como trabalho de filólogos ou estudiosos de culturas antigas, o estudo das fontes nem sempre é levado em conta entre os historiadores da ciência moderna. Todavia, a compreensão das fontes que geraram uma determinada ciência continua sendo uma das melhores formas de averiguar seus trânsitos ou descaminhos entre lugares e épocas, mesmo as mais recentes. Tal averiguação parece de particular interesse tanto no caso da ciência portuguesa quanto da brasileira, cujas origens e processos modernos ainda envolvem muitas controvérsias.

Caberia mencionar, porém, que o estudo das fontes para a realização de uma análise documental foi bastante comum entre os historiadores da ciência, até pelo menos a década de 60 do último século. Basta lembrar o estudo interno a antigos originais de ciência, mantido como praxe ao longo desse período, que desde sempre exigira um trabalho apurado de filologia edótica, ou seja, de crítica textual. Ao que tudo indica, a transposição dessa velha máxima filológica para a história da ciência seria assumida de forma quase natural.

Assim, não é difícil encontrar as marcas desse duro trabalho com as fontes, em obras como as de G. Sarton, J. R. Partington, L. Thorndike e muitos outros. Constantemente às voltas com famílias de manuscritos, buscas frenéticas por raízes de palavras e conceitos, assim como por materiais para 'calafetar' os vazios e falhas dos documentos em análise, essas figuras bem conhecidas ajudariam a estabelecer a crítica textual como parâmetro básico para o desenvolvimento de estudos históricos sobre a ciência. Entre outras coisas, a busca das fontes indiciadas por um documento (por vezes recém descoberto ou mal conhecido) deu a esses autores um caminho bastante seguro para devolvê-lo à sua linhagem histórica, bem como para verificar o encadeamento de formas de pensar que lhe foram anteriores ${ }^{1}$.

Desnecessário dizer que todo esse cuidado visava corrigir leviandades e, até mesmo, enormes equívocos cometidos por alguns estudiosos desde o século XIX. Lembremos que nesse século deu-se a recuperação de um colosso de documentos, essenciais para a história da ciência, mas esquecidos em arquivos e bibliotecas, inclusive tradicionais.

${ }^{1}$ ALFONSO-GOLDFARB, FERRAZ e BELTRAN, A historiografia contemporânea e as ciências da matéria; ALFONSO-GOLDFARB e FERRAZ, Enredos, nós e outras calosidades em História da Ciência. 
Algo que, sobretudo, ocorreu a partir das pesquisas de grandes cientistas, preocupados em encontrar a origem de suas áreas de estudo e oferecer uma medida para o 'progresso' que estas tinham alcançado. Movidas pela ânsia de exibir tal progresso - ou seja, feitas com olhos postos no presente e, portanto, anacrônicas - as análises dessa documentação poucas vezes se beneficiaram de um grande apuro filológico. Enfim, para que buscar as fontes de documentos que, em si, já eram considerados como fontes iniciais das obras presentes? Um exemplo dessa perspectiva de trabalho documental, quase sempre lembrado como clássico, foi o de M. Berthelot. Desde meados do século XIX e pelo resto de sua longa vida, Berthelot incluiu ao lado de seus 'que fazeres' como cientista, educador e estadista bem sucedido, um forte levantamento, estudo e edição de antigos documentos relacionados, especialmente, às origens da química. Praticamente sozinho, encontrou e analisou centenas e centenas de fólios que diziam respeito tanto à ciência grega quanto ao medievo árabe e latino².

Mas, apesar de ter em mãos esse tesouro documental, o interesse de Berthelot não iria além de demonstrar a existência de uma linha histórica, crescente e aprimorada, dos conceitos e práticas do laboratório. Com essa pré-concepção em mente e com a certeza, no mínimo dúbia, de que documentos originais já trazem em si os elementos para sua análise, o destacado químico cometeu erros de toda ordem. Não teve qualquer prurido, por exemplo, de entregar a tradução dos textos em grego e árabe (línguas que, aliás, não dominava) a grandes literatos sem preparo algum em ciências. Assim, sobre essas traduçôes primorosas - mas sem o devido levantamento das fontes para compreensão dos conceitos e práticas ali presentes - Berthelot permitiu-se traçar paralelos diretos com a química de sua época. De maneira semelhante, permitiu-se tomar o lado dos helenistas na tórrida polêmica, então em voga, sobre a primazia e as derivaçōes históricas dos estudos relativos à matéria. Em outras palavras, sua leitura pré-concebida dos documentos (que, em sua maioria, sequer havia traduzido) o induziu a buscar na ciência grega um assento primeiro e absoluto da ciência em árabe e latim ${ }^{3}$.

Berthelot perderia, portanto, uma oportunidade impar de trazer à luz as singularidades e aspectos inéditos do laboratório medieval, apesar de ter produzido a primeira história da química baseada em documentação ampla e original. Consequentemente, as críticas de futuros estudiosos que, por sinal, não demoraram muito a acontecer, foram ferozes.

A pauta para essa crítica já fora ditada, ainda no século XIX, não só por filólogos que haviam trabalhado documentos específicos de ciência antiga e medieval, mas também por um cientista do porte de P. Duhem. Esse físico e filósofo francês, também interessado em encontrar as raízes de sua área, descobriu documentos medievais que haviam permanecido inéditos até aquele momento. Surpreso com a originalidade e precocidade das ideias contidas nesses manuscritos, Duhem dedicou-se a estudá-los. Estabelecidos por ele de forma preliminar, mas já com uma perspectiva de análise e um cuidado filológico bem diferentes aos de Berthelot, os textos desses manuscritos serviriam como base para dar um novo impulso aos estudos de autores medievais como R. Bacon ${ }^{4}$.

${ }^{2}$ Ver, por exemplo, BERTHELOT, La chimie au Moyen Âge e ainda: ALFONSO-GOLDFARB, Algumas consideraçōes históricas e historiográficas sobre os documentos da hermética árabe medieval, pp. 76-80.

${ }^{3}$ Ver, por exemplo, HOLMYARD, A critical examination of Berthelot's Arabic chemistry.

${ }^{4}$ Ver, por exemplo, DUHEM, Un fragment inédit de l'Opus tertium de Roger Bacon. 
No entanto, nunca é demais lembrar que Duhem permitiu-se manter uma segunda agenda em seus trabalhos. Aparentemente por motivos religiosos, esforçou-se por encontrar uma documentação que revertesse a imagem, bastante comum em sua época, de que o mundo cristão medieval esteve mergulhado em trevas, pois afastado do estudo da natureza e das técnicas. Mas, se por um lado seu trabalho ajudou no desmonte dessa imagem, por outro deu elementos suficientes para que a tônica em história da ciência fosse, cada vez mais, a busca por 'precursores' ou 'pais' da ciência moderna. Uma máxima que não abandonaria as futuras gerações de estudiosos, apesar de seu cuidado com as fontes e, de maneira geral, com a documentação original ${ }^{5}$.

Chega-se assim, em meados do último século, a uma história da ciência que não conseguia livrar-se de muitos de seus anacronismos, porque repleta de 'precursores', alguns deles até mesmo trazidos de épocas remotas. Devolvê-los a seu lugar e compreender, em sua própria época, a dimensão efetiva de suas teorias e práticas demandaria levar a sério o estudo do contexto a que pertenceram. Todavia, a centralidade tomada, desde então, pelas análises sobre o contexto parece ter afastado a maior parte dos estudiosos da velha e boa prática de compreender a documentação através de suas fontes. Nem uma, nem outra, mas a conjunção de ambas as formas de estudo será apresentada nos dois exemplos a seguir. Um deles nos traz alguém que, mesmo sendo estrangeiro, foi fundamental para a reforma pombalina da Universidade de Coimbra (Herman Boerhaave). Enquanto o outro refere-se, justamente, a um egresso desta universidade quando já reformada (Vicente Coelho Seabra).

\section{QUANDO AS FONTES NOS CONTAM UMA HISTÓRIA DIFERENTE ÀQUELA DO DOCUMENTO: vozes destoantes Na CorrespondênCIa de Herman BoerhaAve}

Luminar das ciências médicas no século XVIII, H. Boerhaave foi também conhecido por sua habilidade e precisão nos estudos e práticas do laboratório químico. Boa parte desses estudos e práticas visava estabelecer uma relação mais moderna e sólida entre a química e a medicina. Todavia, salta aos olhos o grande número de fontes sobre o antigo laboratório químico/alquímico assimiladas na constituição desse trabalho. Para tanto, Boerhaave teria se valido de sua formação anterior em estudos clássicos, aliás, respeitadíssima por seus contemporâneos e sempre levada em conta em análises futuras sobre a sua obra ${ }^{6}$.

Apesar de todos esses louvores, porém, nossas pesquisas vêm indicando que o uso feito por Boerhaave de suas fontes teria sido um tanto estranho, para não dizer forçado. Entre as várias instâncias, escolhemos trazer aqui uma que indica a permanência de tal procedimento até praticamente o final de sua vida e, inclusive, em documentação reservada.

Trata-se do que teria sido um de seus últimos esforços por encontrar uma espécie de matéria prima dos metais, através da qual acreditava ser possível desenvolver medicamentos dos mais poderosos. Por anos a fio tentaria encontrar esse princípio

\footnotetext{
${ }^{5}$ Para comentários a esse respeito, ver HACKETT, Roger Bacon and the Sciences.

${ }^{6}$ DEBUS, Chemistry and Medical Debate: van Helmont to Boerhaave, em especial os cap. 5 e 6.
} 
metalífico no mercúrio, seguindo o que indicavam a maioria das fontes antigas. Mas, sem sucesso e já cansado e bastante doente, Boerhaave começaria a procurá-lo, como veremos, em materiais distintos ao mercúrio ${ }^{7}$.

Essa busca está registrada em sua correspondência no período a J. B. Bassand, antigo estudante e amigo de Boerhaave. Bassand foi nomeado médico da corte imperial em Viena, tendo viajado para vários lugares onde existiam minas de importância reconhecida. ${ }^{8}$ Talvez por isso, Boerhaave pergunta-lhe em carta de Agosto de 1732, se em suas andanças por essas minas não teria encontrado alguém que conhecesse a forma tomada pela matéria prima dos metais nos veios da terra. Pois, existiria um certo material fluído chamado gur que, segundo havia afirmado G. Agrícola, teria uma consistência gordurosa e, através do calor subterrâneo, formaria os metais. Boerhaave admite nunca ter visto ou obtido esse material. Mas considera que estudá-lo poderia trazer esclarecimentos sobre a transformação/transmutação dos metais e talvez revelar suas propriedades medicamentosas. ${ }^{?}$

O tema volta à baila no final de sua próxima carta quando Boerhaave diz ter consultado a maioria dos autores sobre a história dos metais, encontrando a opinião unânime de que:

“...a primeira coisa encontrada na matriz [das minas] é um óleo fluido, tão denso quanto a gordura, mas normalmente de cor amarelo-esverdeada, e isso é o que os mineiros germânicos chamam em sua própria língua de Guhr; e que a partir disso, após coagulação trazida pela concocção da natureza, toda sorte de metais são formados, como se fosse a partir de uma matéria original, a qual a maioria deles está relacionada de perto". ${ }^{10}$

Ao menos um par de vezes mais, essa insistente descrição, com alguns acréscimos, se repete na correspondência de Boerhaave a Bassand. Em carta de Dezembro de 1732, por exemplo, Boerhaave dirá que, segundo vários autores, o Gur se encontraria no interior das pedras mais duras, como um sabão líquido, um humor metálico solúvel em água, que se considera a matéria prima metalífica. ${ }^{11}$

Naturalmente, Boerhaave sempre lembra a Bassand as propriedades medicinais dessa possível matéria prima dos metais. Mas, vai ainda mais longe, em carta de Dezembro de 1733 onde conjectura que se o ouro tinha origem nessa matéria primeva, talvez esta fosse o próprio 'ouro potável'12, ou seja um dos medicamentos mais cobiçados e inencontráveis de todos os tempos. Guardemos, porém, essa conjectura específica para mais adiante.

${ }^{7}$ Ver ALFONSO-GOLDFARB e FERRAZ, A discussão sobre o princípio metalífico da matéria na Royal Society e a recepção das memórias de H. Boerhaave sobre o mercúrio; ALFONSO-GOLDFARB, FERRAZ e WAISSE, Chemical remedies in the 18th century: mercury and Alkahest .

${ }^{8}$ LINDEBOOM, Boerhaave's Correspondence, part Two, pp. 107 et seq.

${ }^{9}$ LINDEBOOM, op. cit., Boerhaave a Bassand, 3 Agosto 1732, ent. 268, p. 302-305, citação à p. 305 e ainda: ALFONSO-GOLDFARB e FERRAZ, Gur, Ghur, Guhr or Bur?.

${ }^{10} \mathrm{Ibidem}$, Boerhaave a Bassand, 3 de Outubro de 1732, ent. 269, p. 304-311, citação à p. 311.

${ }^{11}$ Ibidem, Boerhaave a Bassand, 31 de Dezembro de 1732, ent. 270, pp. 310-315; citação à p. 313; ênfase nossa.

${ }^{12}$ Ibidem, Boerhaave a Bassand, 8 de Dezembro de 1733, ent. 274, pp. 324-329; citação à p. 327. 
Por enquanto, lembremos apenas que Boerhaave se interessa pelo gur, pois, acompanhando suas fontes, ainda acredita na existência de um princípio metalífico. Em seus diálogos com Bassand, aliás, terá que lançar mão de um conjunto de autores dos mais tradicionais em alquimia, iatroquímica e estudos das minas. Nomeados explicitamente, em uma de suas cartas a seu antigo aluno, encontram-se autores tão dispares como o notável, mas tradicionalmente aristotélico, estudioso quinhentista G. Agrícola, cujo trabalho sobre minas marcou época. Ou, em contra-partida, o não menos famoso J. B. van Helmont, conhecido e reconhecido como o maior dos paracelsistas e iatroquímicos do século XVII. ${ }^{13}$ Vejamos de perto o que dizem essas duas fontes citadas por Boerhaave. Mas, sem esquecer que para ele, todos os autores interessados na história dos metais teriam dito algo sobre o $g u r .{ }^{14}$

Agrícola - o primeiro a ser indicado na série de cartas a Bassand em que o gur é mencionado - segundo Boerhaave, teria se referido a essa matéria prima como um tipo de "gordura ou adiposidade cerosa" que formaria metais maduros através do calor subterrâneo. De fato, Agrícola dedica, em seu De ortu \& causis subterraneorum..., todo um livro à geração, à causa e à natureza dos minerais onde, acompanhando de perto e desenvolvendo argumentos aristotélicos, refere-se a um certo sucus que seria a matéria prima metalífica ${ }^{15}$. Todavia, boa parte desse livro seria usada por Agrícola para refutar as concepções alquímicas, não só a respeito da transmutação, mas sobretudo aquelas referentes à geração dos metais no seio da terra.

Primeiramente argumenta contra a tradicional teoria do mercúrio e enxofre, dizendo que por muitos séculos esta se estendeu e contaminou "com suas razões astutas e loucas" mesmo quem trabalhava nas minas ${ }^{16}$. E, encerra dizendo que raramente veios de mercúrio e enxofre puros se encontram próximos aos veios dos metais. ${ }^{17}$

Mas será na sua segunda refutação às idéias alquímicas onde mencionará uma matéria gordurosa com as mesmas características de gur. Entretanto, ao contrário do que diz Boerhaave, Agrícola contesta qualquer possibilidade de que os metais se engendrem a partir dessa matéria gordurosa. Alega, por exemplo, que o humor gorduroso, inato de animais e plantas, seria a causa principal de sua fácil combustão. Aliás, ninguém teria podido explicar esse humor gorduroso nos metais, a não ser que fosse derivado "... da sarna de Alquimistas infectados". ${ }^{18}$

Nada muito diferente do que foi visto até aqui pode ser encontrado em outras partes da obra de Agrícola referentes aos metais. ${ }^{19}$ Todavia, parece pouco provável que um exímio latinista como foi Boerhaave tenha lido algo inexistente na obra de Agrícola, ou no mínimo se equivocado em suas leituras. Fica, assim, um primeiro interrogante sobre as fontes usadas por Boerhaave em suas investigações a respeito do gur.

\footnotetext{
${ }^{13}$ Ibidem, Boerhaave a Bassand, 3 de Outubro de 1732, ent. 269, pp. 310-11.

${ }^{14}$ Ibidem, Boerhaave a Bassand, 3 Outubro 1732, ent. 269, pp. 304 et seq.; 8 de Dezembro de 1733 ent. 274, pp. 325 et seq.

${ }^{15}$ AGRICOLA, De ortu \& causis subterraneorum; para esta pesquisa utilizamos a tradução De la generatione.

${ }^{16} \mathrm{Ibiem}, \mathrm{f} .67 \mathrm{v}$

${ }^{17}$ Ibidem, ff. 67v-69. Embora não faça referência, Agrícola tem, certamente como fonte, para essa argumentação, o quadro oferecido por AVICENA em seu De congelatione.

${ }^{18}$ AGRICOLA, De generatione, ff. 73-74v.

${ }^{19}$ Ver em seu De la natura de cose fossili, in: De ortu \& causis subterraneorum, ff. 182-182v.
} 
Diferente de Agrícola, van Helmont - outra das fontes citadas explicitamente por Boerhaave - indica, em vários de seus tratados, a existência nos veios da terra de uma matéria a que os mineiros chamariam de Bur. Essa matéria, em tudo semelhante ao gur, seria equivalente a um sabão líquido encontrado nas fendas e fissuras das pedras. Essa forma de suco ou fluido, presente no canais subterrâneos segundo van Helmont, era “... a primeira semente da vida metálica”, desconhecida pelo homem, porque engendrada nas profundezas. ${ }^{20}$

Em outro momento, van Helmont explica que o bur seria um tipo de seiva mineral, assim como havia a dos vegetais. Ambas geradas a partir de uma espécie de princípio terroso que, por sua vez, se originava da água primordial. ${ }^{21} \mathrm{O}$ bur, em lugares secos, ou lugares onde a penetração da água fosse impedida, geraria os metais. ${ }^{22}$

Longe, portanto, das indicações de Boerhaave, van Helmont afirma com clareza que o bur seria uma etapa importante, mas apenas intermediária, entre o elemento primordial (água) e os metais. E, isso sem mencionar a discussão, já em autores do próprio século XVII - por sinal bem conhecidos por Boerhaave -, sobre se a troca da palavra gur por bur teria representado um mero lapso ou erro de grafia cometido por van Helmont; ou se foi sua tentativa de expressar concepções diferentes. ${ }^{23}$

Novamente nesse caso, assim como no anterior, fica um interrogante sobre o uso feito por Boerhaave de suas fontes. Parece difícil considerar que alguém com seu preparo e destreza tenha, simplesmente, se enganado em algo que fundamentava seus estudos no período. Sem esquecer que se trata de uma correspondência, onde o grau de liberdade sempre é maior, valeria insistir, mais uma vez que, essa maneira engenhosa de fazer com que as fontes contassem o que pretendia, encontra-se com frequência em sua obra. E, quase em geral, as análises têm indicado uma agenda ainda em formação, mas muito mais ampla do que a declarada, por detrás desse procedimento pouco recomendável.

Sem dúvida, as buscas de Boerhaave por um princípio metalífico ocupam um lugar central na correspondência em tela. Todavia, a sua insistência sutil, porém constante, nas implicaçóes médicas que isto traria, nos leva diretamente à única instância específica mencionada por ele que, como indicado acima, refere-se ao 'ouro potável'. Assim, após sugerir a possível equivalência entre o inestimável medicamento e o gur, ele dirá a Bassand que, uma maneira simples de comprovar sua tese, seria conseguir uma amostra desse material, de fácil obtenção entre os mineiros, para ministrá-lo cuidadosamente aos pacientes. Dessa forma, considera que seria possível conhecer melhor os 'processos' com o ouro potável, já que seus estudiosos teriam se movido muito e avançado quase nada. ${ }^{24}$

${ }^{20}$ VAN HELMONT, Magnum oportet. [entrada 39], in Ortus medicianae, p. 157.

${ }^{21}$ VAN HELMONT, Elementa [entradas 11-13], in Ortus medicianae, p. 53.

${ }^{22}$ VAN HELMONT, Aqua [entradas 5-7], in Ortus medicianae, p. 58.

${ }^{23}$ Veja-se, por exemplo, os comentários sobre essa questão na obra de J. WEBSTER, Metallographia: or, An history of metals, pp. 52-3; embora não declarada, boa parte da trilha sobre o gur e suas fontes, seguida por Boerhaave, já se encontra nesta obra seiscentista que, desde então, tornou-se referência obrigatória nos estudos mineralógicos e metalúrgicos, não só históricos como até mesmo práticos.

${ }^{24}$ Sequência da carta de 8/12/1733, supracitada. 
Não é difícil perceber que nos meandros dessa sugestão tentadora encontra-se, na verdade, uma forma elegante de pedir uma amostra de seu tão desejado gur, ao antigo discípulo e colaborador. Como também não é difícil perceber que o próprio Boerhaave devia constar na lista, criticada por ele, dos que quase nada tinham avançado na obtenção do ouro potável.

De fato, a única entrada para ouro potável em toda sua obra publicada, encontra-se no índice dos Elementos de Química e tem relação com o que promete ser "A Preparação do Sulfur com um ácido e um álcool”. O ácido seria o "Óleo de Vitriol”, gotejado lentamente sobre álcool bem puro, livre de álcalis. A mistura era aquecida suavemente durante 5 dias e depois levada à destilação, sempre em fogo suave. Os diferentes 'licores' obtidos - recolhidos em diferentes recipientes - apresentavam cheiros adocicados ou fétidos. As escórias, negras, diluídas em água, dão novamente "um Óleo de Vitriol ácido". Nenhum Enxofre se forma nessa operação, diz Boerhaave, ainda que algumas de suas propriedades fossem manifestas. Também o Óleo de Vitriol seria diferente daquele empregado no início, observa Boerhaave: "Portanto, pode-se ver quantos e quão inesperados Phoenomema surgem dessa Combinação". Boerhaave se pergunta se o material obtido seria o Spiritus Vini Philosophorum de que fala Lúlio, ou o Spiritus Vitrioli Dulcis de Paracelso. E completa:

“...seria com isso que se obtém a Tintura de Ouro de Paracelso, de maneira a fazer um Aurum Potabile, digerido, como ele diz, no Estômago de um Avestruz? Essa Operação certamente deve animar os curiosos a examiná-la. Com prudência, porém, caso algum desses grandes Arcana esteja aí encoberto. "25

Sempre íntimo das suas fontes - e por isso autorizado a manejá-las quando assim lhe prouvesse - Boerhaave parece aqui escutá-las. E, mais ainda, faz coro com elas ao assumir a existência de grandes Arcana não revelados no ouro potável. A equivalência entre este e o gur - um corpo palpável, embora pouco conhecido - poderia ser a forma de evidenciar tais Arcana, diretamente relacionados aos princípios da matéria.

\section{QUANDO A ESCUTA DAS FONTES REMOVE ESTRANHEZAS DO DOCUMENTO:} VOZES QUe Falam EM VÁRIAS LÍNGUAS Na ObRa de Vicente SEABra

Considerado como o primeiro livro, em português, baseado na química moderna ${ }^{26}$, o Elementos de Chimica de Vicente Seabra teria, ainda, outro grande mérito. Uma vez que essa, então, 'nova' ciência estaria fundamentada na publicação, em 1789, do Traité élémentaire de chimie, de A.-L. Lavoisier, o livro de Seabra, cuja primeira parte veio à luz já em 1788 , seria anterior ao do grande químico francês. ${ }^{27}$

${ }^{25}$ BOERHAAVE, Elements of Chemistry, vol. II, Process CLXI, pp. 303-4.

${ }^{26}$ FILGUEIRAS, Vicente de Seabra Telles, the First Brazilian Chemist.

${ }^{27}$ Vide C. SEABRA, Elementos da Chimica; para mais detalhes, ver de nossa autoria, As ciências em Portugal e no Brasil, pp. 154-159; ver ainda ALFONSO-GOLDFARB e FERRAZ, A recepção da química moderna no Brasil. 
No entanto, a anterioridade dessa obra sempre causou certa estranheza. No mínimo, porque isso contrastaria com as persistentes mençôes sobre a necessária 'influência' francesa para o surgimento dos primeiros trabalhos portugueses em química moderna. Decidimos, assim, verificar mais de perto essa suposta estranheza, através de um estudo preliminar das fontes que compuseram o livro de Seabra. ${ }^{28}$

Esse brasileiro, nascido nas Minas Gerais, inicia seus estudos em Coimbra, em 1783, a partir do Curso Filosófico (então obrigatório para quem fosse estudar medicina) e, desde o começo, interessa-se por tudo que dissesse respeito à química. Talvez por isso, em seu Elementos de Chimica, Seabra decide fazer uma espécie de revisão comentada desse campo de estudos, apresentando uma Historia da Química, dividida em seis épocas. A última dessas épocas seria, justamente, o presente, onde Seabra diz ser possível reconhecer três teorias principais sobre os fenômenos químicos. Estas seriam a "Stabliana, Pneumática, e Media", que Seabra descreve, brevemente, abordando em especial os trabalhos sobre os chamados "novos ares" e sua participação na composição da matéria. Naturalmente, a primeira teoria estava relacionada ao bem conhecido flogístico de Stahl. Já a segunda teoria (ou seja, a Pneumática) estaria ligada a Lavoisier, a partir de suas demonstraçōes de que o ar 'puro' se combinava com os corpos. Enquanto a terceira, chamada por ele de "Média", remetia ao nome de J.-P. Macquer, que admitia a luz combinada com os corpos, no lugar do flogístico de Stahl. ${ }^{29}$

Todavia, Seabra lembra que essa "teoria media" foi também admitida por Lavoisier, com uma pequena, mas importante, diferença: "o phlogisto, ou materia do calor, não se separava dos corpos, como pensava Macquer, mas do ar, que se combinava com elles, que então se decompunha". Fourcroy, a quem Seabra declara dever a maior parte de seus conhecimentos químicos, também teria abraçado essa "teoría media". No entanto, Seabra prossegue dizendo: "exporemos huma pouco diferente desta, e mostraremos, que a de Macquer junta com a de Lavoisier parece a verdadeira que devemos seguir". ${ }^{30}$ De fato, aproximadamente três dezenas de páginas mais adiante, Seabra dirá que:

“a combustão he a combinação dos corpos com o oxyginio, e o desenvolvimento do phlogisto, deste somente, ou tambem do corpo segundo a natureza do residuo. Esta nossa theoria he fundada sobre a mesma natureza dos corpos, e as novas experiencias de Kirwan sobre o calor especifico". ${ }^{31}$

Nesse ponto, nosso autor introduz um nome mais, o de R. Kirwan que, desde suas nativas Ilhas Britânicas, contestara as ideias químicas chegadas do Continente. Assim, teria proposto, em seu Essay on Phlogiston and the Constitution of Acids, publicado em 1787, as mesmas ideias, anteriormente, expostas por Seabra. ${ }^{32}$ Isso mostra que Seabra

${ }^{28} \mathrm{O}$ estudo aqui referido é parte do supracitado, As ciências em Portugal e no Brasil.

${ }^{29}$ SEABRA, Elementos da Chimica, op. cit., p. 8; os destaques são do próprio autor; ver, ainda, de nossa autoria, O processo de transformação da teoria do flogístico no século XVIII, especialmente os caps. II, III e IV.

${ }^{30}$ SEABRA, Elementos da Chimica, op. cit., p. 9.

${ }^{31}$ Ibidem, p. 35.

${ }^{32} \mathrm{O}$ texto de Kirwan foi traduzido ao francês por Madame Lavoisier, recebendo longas notas do próprio Lavoiser, além das de Guyton de Morveau, P. S. de la Place, G. Monge, C.-L. Berthollet y A.-F. de Fourcroy: Essai sur le phlogisitque et sur la constitution des acides. 
era um bom conhecedor das últimas publicações em química realizadas em outros centros. Por isso mesmo, teve a capacidade de discutir e incorporar - quando acreditava conveniente - as novas ideas. ${ }^{33}$

Outros aspectos do texto de Seabra merecem nossa atenção: aqueles relacionados com o que considera as partículas constitutivas dos corpos. Aqui, novamente, comprovamos um afastamento entre o autor luso-brasileiro e a grande 'influência' francesa de Lavoisier. Comecemos expondo, ainda que brevemente, algumas das ideias do mestre francês.

Já no prefácio de seu Traité élémentaire de chimie, Lavoiser nos informa que seu primeiro objetivo era tornar ainda mais claras as ideas expostas na memória que abre o Méthode de Nomenclature Chimique, publicado dois anos antes, em co-autoria com Guyton de Morveau, C.-L. Berthollet y A.-F. de Fourcroy. Por sua vez, o objetivo desse trabalho havia sido criar para a química uma 'língua' que pudesse ser considerada como um método analítico, permitindo, como a álgebra, desvendar o desconhecido através do conhecido. ${ }^{34}$

Lavoisier e seus colegas da Academia de Ciências, autores da série de memórias que compõem o Méthode de Nomenclature Chimique, tinham clareza de que denominar os materiais da forma por eles proposta, seria também aceitar as mais novas ideas sobre a composição da matéria. Algo que demandava assumir a definição dos "princípios constitutivos dos corpos", ou "sustâncias simples" como sendo "tudo que obtemos ao final das análises químicas", uma vez que os materiais conhecidos deveriam ser denominados segundo suas partes mais diminutas.

Ou seja, qualquer material que se quisesse nomear, deveria passar por uma análise química, até que não fosse mais possível decompô-lo. Caso não se conhecesse as partículas assim obtidas, estas deveriam ser identificadas e nomeadas, a fim de que seus nomes pudessem também fazer parte daquele atribuído ao material original.

Lavoisier define, ainda, em seu Traité élémentaire de chimie, o que seria o "elemento químico" e escreve um "capítulo sobre as partes constitutivas e elementares dos corpos". 35

Dessa maneira, o texto de Lavoisier trata, em sua primeira parte, "da formação dos fluidos elásticos aeriformes e sua decomposição; da combustão dos corpos simples e a formação de ácidos". Isso significava pensar, desde o inicio, na combinação do calórico para formar, segundo as ideas do período, um dos fluidos aeriformes: o oxigênio. O passo seguinte envolvia a 'decomposição' do oxigênio e sua combinação com os diversos corpos simples (como o fósforo, o enxofre, o carbono, o gás hidrogênio, etc.) durante o fenômeno da combustão. Após discutir a formação e decomposição dos diversos materiais, Lavoisier nos apresenta uma "tabela das sustâncias simples", definidas da maneira que comentamos anteriormente. ${ }^{36}$

${ }^{33}$ A Dissertação sobre o calor foi publicada em Coimbra, em 1788; ver o artigo de A. M. AMORIM DA COSTA, Da natureza do fogo e do calor na obra de Vicente de Seabra (1764-1804), pp. 137 e 151; ver, ainda, nosso livro supracitado, As ciências em Portugal e no Brasil, pp. 154 et seq.

${ }^{34}$ Mais detalhes sobre estas questóes podem ser encontrados em: FERRAZ, La recepción y La difusión de la Química 'francesa' en Portugal en los siglos XVIII y XIX, esp., pp. 198-204.

${ }^{35}$ LAVOISIER, Traité élémentaire de chimie, pp. xiv-xv.

${ }^{36}$ Ibidem, p. 192. 
Seabra, por sua parte, apresenta um item denominado Dos principios geraes dos Corpos, quando trata do fogo, do ar e da água que não seriam, no entanto,

“os únicos princípios dos corpos, e nem verdadeiramente elementos; nós os contemplaremos como huns dos principios geraes dos compostos, não só porque em todos estes sempre se acha alguns delles, ou todos juntamente, mas porque pretencem a todos os tres reinos". ${ }^{37}$

Logo após, Seabra fala de cada um desses 'princípios', antes de tratar Das Operaçoens Geraes da Chimica, finalizando, assim, a primeira parte do livro, dedicada à Chimica Theorica.

A segunda parte, denominada Chimica Theorica e Practica, começa pela discussão de como pretende organizar seu livro, pois, segundo ele, não se deve seguir a divisão da Historia Natural - portanto, colocando os corpos nos três reinos -, uma vez que nos três reinos se encontram materiais com as mesmas propriedades. Assim, Seabra divide:

“todos os corpos debaixo de duas Classes, Incombustiveis, e Combustiveis. A 1a. dividimos em 3 Ordens Terra, Substancias Salino-terreas, e Saes : a 2a . em duas, Combustiveis por si, e Combustiveis não por si, e cada huma destas Ordens em varios Generos, e Especies."

De toda maneira, Seabra toma emprestado da História Natural - seguindo, provavelmente Fourcroy em uma de suas publicaçôes - um modelo classificatório para apresentar os materiais conhecidos, que são descritos, um após o outro, notoriamente por suas propriedades. ${ }^{38}$ É verdade que Seabra adota a nova nomenclatura proposta pelo grupo francês. Todavia, ao elaborar seu texto não parte dos 'princípios'- o que seria mais coerente com as novas ideias de Lavoisier - mas dos corpos compostos, tratando, eventualmente, de sua composição. Mantém, assim, aspectos da 'antiga' química.

Por outro lado, a análise preliminar feita até aqui sobre a obra de Seabra nos mostra - antes mesmo de abordar à parte central de seu texto - que o estudioso luso-brasileiro busca envolver várias das teorias químicas de sua época, não optando pelas ideias puramente de Lavoisier. Bastaria lembrar que, uma das ideias fundamentais abraçadas por Lavoisier e condutora de sua obra - a definição de elemento químico - não será determinante no livro de Seabra.

\section{Agradecimento}

À FAPESP - Fundação de Amparo à Pesquisa do Estado de São Paulo, CNPq Conselho Nacional de Desenvolvimento Científico e Tecnológico e University College London.

${ }^{37}$ SEABRA, Elementos de Chimica, op. cit., p. 19-20.

${ }^{38}$ Ver As ciências em Portugal e no Brasil, pp. 156-9; e também ACEVES PASTRANA, Química, Botánica y Farmacia en la Nueva España, p. 22 et seq. 


\section{REFERÊNCIAS}

ACEVES PASTRANA, Patricia - Química, Botánica y Farmacia en la Nueva España a finales del siglo XVIII. México DF: Universidade Autónoma Metropolitana, 1993.

AGRICOLA, Georgius - De la generatione de le cose. Veneza: Michele Tramezzino, 1550.

AGRICOLA, Georgius - De re Metallica. Trad. Herbert Clark Hoover, Lou Henry Hoover. New York: Dover, 1950.

ALFONSO-GOLDFARB, Ana Maria - Algumas consideraçôes históricas e historiográficas sobre os documentos da hermética árabe medieval. In FORMOSINHO, Sebastião, org; BURROWS, Hugh. D., org. Sementes de Ciência: Livro de homenagem António Marinho Amorim da Costa. Coimbra: Univ. de Coimbra, 2012. p. 67-84.

ALFONSO-GOLDFARB, Ana Maria e FERRAZ, Márcia Helena Mendes - A recepção da química moderna no Brasil. Quipu. Vol. 7 (1990), p. 73-91.

ALFONSO-GOLDFARB, Ana Maria e FERRAZ, Márcia Helena Mendes - A discussão sobre o princípio metalífico da matéria na Royal Society e a recepção das memórias de H. Boerhaave sobre o mercúrio. In MARTINS, Roberto de Andrade [et al.] Filosofia e história da ciência no Cone Sul. $3^{\circ}$ Encontro. $2^{a}$ edição. Campinas: Associação de Filosofia e História da Ciência do Cone Sul, 2008.

ALFONSO-GOLDFARB, Ana Maria; FERRAZ, Márcia Helena Mendes - Enredos nós e outras calosidades em História da Ciência. In ALFONSO-GOLDFARB, Ana Maria, org. [et al.] Centenário Simão Mathias: documentos, métodos e identidade da História - seleção de trabalhos. São Paulo: PUC-SP/Imprensa Oficial, 2009. p. 25-36.

ALFONSO-GOLDFARB, Ana Maria; FERRAZ, Márcia Helena Mendes - Gur, Ghur, Guhr or Bur? The quest for a metalliferous prime matter in early modern times. British Journal for the History of Science. (2011) 1-15.

ALFONSO-GOLDFARB, Ana Maria; FERRAZ, Márcia Helena Mendes; BELTRAN, Maria H.R. - A historiografia contemporânea e as ciências da matéria. In ALFONSO-GOLDFARB, Ana Maria, org [et al.]. Escrevendo a História da Ciência: tendências, propostas e discussōes historiográficas. São Paulo: Educ [etc.], 2004. p. 49-73.

ALFONSO-GOLDFARB, Ana Maria ; FERRAZ, Márcia Helena Mendes; WAISSE, Silvia - Chemical remedies in the 18th century: mercury and Alkahest. Circumscribere. ISSN 1980-76-517: 19-30.

AVICENA - De congelation. Trad. e notas de Eric John Holmyard; Desmond Christopher Mandeville. Paris: Lib. Orientaliste P. Geuthner, 1927.

BERTHELOT, Marcellin - La chimie au Moyen Âge. Osnabrück : Otto Zeller ; Amsterdam : Philo press, 1967. BOERHAAVE, Herman - Elements of Chemistry being the Annual Lectures...Trad. de Timothy Dallowe. Londres: J. and J. Pemberton, 1735.

COSTA, A. M. Amorim da - Da natureza do fogo e do calor na obra de Vicente de Seabra (1764-1804). In CONGRESSO HISTÓRIA DA UNIVERSIDADE. Universidade(s) : história, memória, perspectivas : actas. [S.l.: s.n.], 1991, 3.

DEBUS, Allen .G. - Chemistry and Medical Debate: von Helmont to Boerhaave. Canton: Science History Publication, 2001.

DUHEM, Pierre - Un fragment inédit de l'Opus tertium de Roger Bacon. Quaracchi: ex typographia Collegii S. Bonaventurae, 1909.

FERRAZ, Márcia Helena Mendes - O processo de transformação da teoria do flogístico no século XVIII. São Paulo: Universidade de São Paulo, 1991. 195 p. Dissertação de Mestrado.

FERRAZ, Márcia Helena Mendes - As ciências em Portugal e no Brasil (1772-1822): o texto conflituoso da química. São Paulo: Educ [etc.], 1997. 255 p.

FERRAZ, Márcia Helena Mendes - La recepción y La difusión de la Química 'francesa' en Portugal en los siglos XVIII y XIX. In ACEVES PASTRANA, Patricia, org. Las Ciências Quimicas y Biológicas a La Luz de sus Fuentes Históricas. México DF: Univ. Autónoma Metropolitana, 2004.

FILGUEIRAS, Carlos A. L. - Vicente de Seabra Telles, the First Brazilian Chemist. Schriftenreihe Für Geschichte Der Naturwissenschaften Technik Und Medizin 27 (1991) 27-44.

HACKETT, Jeremiah - Roger Bacon and the Sciences: Commemorative Essays. Leiden: Brill, 1997.

HELMONT, Jean Baptiste van - Ortus medicianae, id est, initia physicae inavdita. Progressus mediciane novus, in morborum ultionem, ad vitam longam. Amsterdam: Ludovivum Elzevirium, 1648.

HOLMYARD, E. J. - A critical examination of Berthelot's Arabic chemistry. Isis. 6: 479-99.

KIRWAN, Richard - Essai sur le phlogisitque et sur la constitution des acides. Paris: rue et hôtel Serpente, 1788.

LAVOISIER, Antoine-Laurent de - Traité élémentaire de chimie, présenté dans un ordre nouveau. Paris Cuchet, 1789.

LINDEBOOM, Gerrit Arie, org. - Boerhaave’s Correspondence. Leiden: E.J. Brill, 1964. Pt. 2.

SEABRA, Vicente Coelho de - Elementos da Chimica. Coimbra: Real Officina da Universidade, 1985. 2 vol. Ed. facsimilada.

THORNDIKE, Lynn - History of Magic and Experimental Science. New York: Macmillan, 1923-1958. 8 vol. WEBSTER, JOHN - Metallographia: or, An history of metals. Londres: Walter Kettilby, 1671. 